\title{
Crime Prevention in Ethnic Areas Focusing on Crime Prevention through Environmental Design
}

\author{
Seok-Jin Kang \\ School of Architecture, Gyeongsang National University, Jinju-Si, Korea. \\ Email: cpted@gnu.ac.kr \\ Received February $16^{\text {th }}, 2013$; revised March $17^{\text {th }}, 2013$; accepted March $26^{\text {th }}, 2013$
}

\begin{abstract}
The purpose of this study is to consider crime prevention measures in ethnic areas focusing on Crime Prevention through Environmental Design (CPTED) by an analysis of crime data and field survey. In this study, it was found that the main type of foreign crime that occurred in the research area was violence, and crimes committed by Koreans, which were mainly violence and crimes such as burglary, theft, robbery, and sexual offences, occurred steadily. Because it was found that crimes were related to the urban planning elements comprised of land use such as traditional market, inn, pub, and complicated space structure and the architectural design for natural surveillance and security facilities such as CCTV, lighting, alarm, and target hardening device, a new strategy for crime prevention design should include street environmental management, improvement of commercial facilities, and reinforcement security device of each buildings has to be spread through support of policy. In conclusion it was thought that CPTED would be a valuable measure to prevention crime and support community activities in ethnic area as expecting an improvement of physical environment and resident participatory for safer community.
\end{abstract}

Keywords: Crime Prevention through Environmental Design (CPTED); Foreign Crime; Ethnic Area; Hot-Spot; Architectural Design; CCTV

\section{Introduction}

One of the most significant current discussions in Korea is the social problem of the proliferation of the number of foreign workers' residences [1,2]. More specifically, the foreign residential areas in Korea have especially designated, and the discussion is centered on whether crime in those areas is related to their personal and socio-cultural characteristics or physical environmental components [1-5]. In the field of architecture and urban planning, Crime Prevention through Environmental Design (CPTED) is an important research theme that studies environmental measures consisting of crime-inducing or deterring factors [6]. However, so far, there has been little discussion about the crime of foreign residents within CPTED.

In this respect, it is necessary to analyze environmental factors related to crime in the ethnic areas. With this problem in mind, this study explores crime prevention measures through a theoretical study of CPTED, a literature review, an analysis of crime data, a field survey of ethnic areas, and a comprehensive analysis of the relationship between criminal acts and environmental factors.

The scope and process of this study are as follows: 1) a statistical and spatial analysis of the National Police Agency's crime data; 2) a literature review and composition of a checklist for the field survey; 3) a field survey based on the analysis of the crime data; and 4) discussion of crime prevention measures focusing on CPTED.

\section{Theoretical Study and Literature Review}

\subsection{CPTED}

CPTED has emerged and been given considerable academic and administrative attention recently as a new paradigm and an important dimension in crime prevention. CPTED, as proposed by C. Ray Jeffery (1972) [7], is a theory for crime prevention and community activation composed of five design principles: natural surveillance, access control, territoriality reinforcement, activity support, and maintenance [6]. CPTED is applied in the area of architectural and urban planning to eliminate of criminal opportunities through a comprehensive analysis of three main elements that lead to crime: motivated criminals, vulnerable victims, and environmental opportunities [8-10]. CPTED is included in the field of Environmental Criminology because it is theory about the relationship between the environment and crime. 


\subsection{Literature Review}

(1) Studies on the CPTED

Studies on the CPTED originating in the U.S. and Great Britain have increasingly put stress on the development of architectural and urban design guidelines, an analysis of the environmental characteristics of crime hot-spots, and the crime prevention effect and industries related to CPTED, which are institutionally supported in developed countries. According to the foreign countries' studies, there are specific environmental factors that affect offenders' behavior and decision making. These factors are directly or indirectly related to psychological and behavioral elements, such as the residents' attachment to their homes, neighborhood relationship, informal social control, and territoriality (e.g. sense of ownership) and to physical elements, such as estate layout and dwelling characteristics [11-22]. However, studies on the relationship between crime and environmental elements in ethnic areas that focus on CPTED or environmental criminalogy are considered insufficient.

Conversely CPTED in Korea has been developing since the 2000s, and most of the studies are focused on crime and disorder in apartment complexes [23]. Studies on the crime pattern analysis of and CPTED application to detached houses, multi-family houses, and residential areas are unsatisfactory. Similar to the results of foreign countries' studies, Korean studies have verified that crime and fear of crime are related to factors including physical elements, such as the ratio of dwellings to other buildings, estate layout (e.g., the location of windows and entrances for natural surveillance), dwelling characteristics, alleyway structures, the number of intersections, and the density of street lighting and CCTV, and to psychological and behavioral elements, such as territoryality (range of living conditions), the solidarity of the community, and natural or organized surveillance [23, 24].

(2) Studies on ethnic areas

Studies on foreign crime in ethnic areas [1-5] can be organized into the sub-categories of "the study on the relation between ethnic places and dwelling environment" and "the study on the public security and foreign crime in ethnic places." The former sub-category has mainly been studied in the fields of geography, architecture, and urban planning, whereas the latter sub-category has been studied in criminology, penology, and police public administration. Although interdisciplinary studies about the characteristics of foreign crime and ethnic areas focusing on CPTED have not been sufficient, the literature review about them can be summarized as follows: 1) Foreigners are clustered in the specific areas; 2) Foreign residential areas in Korea are deteriorating due to a lack of urban infrastructure and the location of clus- tered multi-family housings adjacent to the manufacturing industries and traditional markets; 3) The rate of foreign crimes has increased steadily; 4) The causes of foreign crimes seem to be linked to social and physical factors such as cultural conflict, racial discrimination, and the vulnerability of the environment.

\section{Summary of This Research}

\subsection{Method of Field Survey and Data Analysis}

(1) Method of field survey

Principles of the research area selection as follows: 1) Foreigners are clustered in the specific areas; 2) There is a similarity between ethnic areas in respect of size and population composition; 3) They are different in physical characteristics of environment between ethnic areas. To select the research areas with these conditions, reported foreign crimes were reviewed with the help of the National Police Agency. The researcher focused on ethnic areas in which foreign migrant workers were clustered within city limits and selected Garibong-dong in Seoul and Wongok-dong in An-san. There are many migrant workers from China in Garibong-dong and foreign migrant workers from Southeast Asia in Wongok-dong. These areas have attracted growing interest in their various crime problems and have experienced a remarkable increase in the number of foreign workers since the early 1990s. Field survey was carried out in target areas by checklist in October 2012 and the checklist was made from theoretical-based on CPTED principles.

(2) Method of data analysis

In this study, the general tendency of crime in the years 2001-2011 was analyzed, and crime hot-spots of the five types of crime (murder, burglary, rape, robbery, and violence) in the research areas in 2011 were analyzed. The Geographic Information System (GIS) ArcMap 9.3 was used to analyze the crime hot-spot and the Statistical Package for Social Science (SPSS) was used to analyze the crime frequency.

\subsection{The Trend of Foreign Crime in Korea}

According to the National Police Agency's statistical data on foreign crimes, the rate of foreign crimes increased remarkably between 2001 (4328 arrests) and 2011 (27,144 arrests) (refer to Figure 1). The national origins of foreign offenders in 2011 were ranked as follows: China (15,667 persons, 58\%); Vietnam (2438 persons, 9.1\%); the United States (1788 persons, 6.6\%); Mongolia (1,503 persons, 5.6\%); and Thailand (944 persons, $3.5 \%$ ). The incidence of the five types of crime (murder, burglary, rape, robbery, and violence) committed by foreign offenders among total crimes was higher than that of domestic offenders. The rate of the five types 


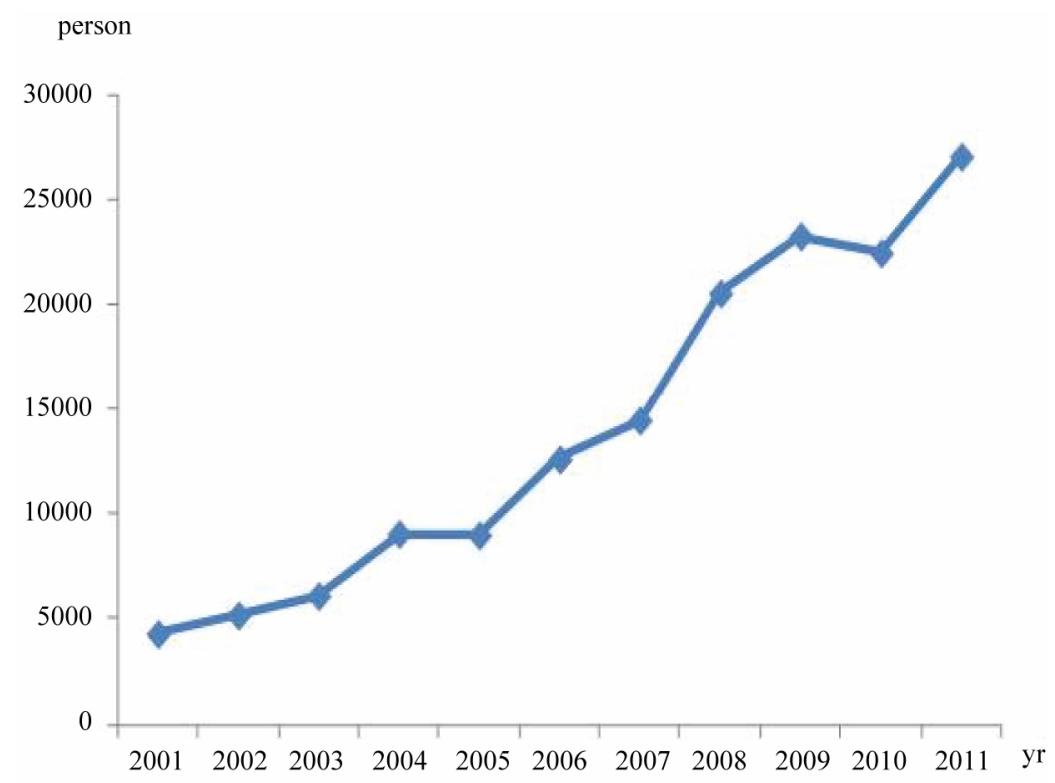

Figure 1. Trend of foreign crimes in Korea in the years 2001-2011.

of crimes by foreign offenders in 2011 was $37.8 \%$, whereas the rate by domestic offenders was $28.0 \%$. Of the five types of crime, the rate of violence was the highest.

\section{Discussion of Results}

The hot-spots were inferred through the spatial analysis of foreign residents, and the field survey was carried out according to the results of the hot-spot analysis. The field survey checklist was composed of CPTED principles, and a Likert scale (a three-point scale) was used to assess comprehensive items. The field survey was carried out on the streets (or alleys), in residential areas, and in commercial areas through the research's subjective judgment.

\subsection{Case of Garibong-Dong}

(1) Analysis of crime spots

The number of crimes that occurred in 2011 was 342. The cases of Korean crime numbered 223 (burglary - 19, robbery and sexual offence-7, violence-197), and the case of foreign crime numbered 119(burglary, robbery, and rape -8 , violence-111). Foreign crimes were linearly concentrated in the surroundings of commercial facilities and the traditional market located between a subway station and a five-way crossing. In addition, some crimes were occurred in a scheduled redevelopment area. The hot-spots of crimes committed by Korean were especially concentrated in the deteriorating residential areas as shown in Figure 2.

(2) Field survey results

The present conditions of alleyway, residential area, and commercial area in Garibong-dong are as shown in Figure 3.

a) Alley and street

In the natural surveillance aspect, there were insufficient streets lighting and narrow and curved paths that connected continually and repeatedly. Moreover, the cars parked randomly on the street obstructed a pedestrian passage and sightline to the surroundings. In the access control aspect, there were insufficient CCTV and burglar alarms. In the territoriality reinforcement aspect, the information map and signboard were inadequate in terms of number, location, and legibility. In the activity support aspect, there were not leisure spaces and sport facilities for the local community. It is supposed that the narrow and complicated paths and spatial structure contributed to these conditions. In the maintenance aspect, there were insufficient cleaning of the paths and management of the street facilities.

b) Residential area: detached houses, multi-family houses, and row houses

Because deteriorated houses of various sizes stood close together in this neighborhood and the traditional market was adjacent to the houses, there was a considerable transient population and, as a results, the possibility for various crimes to occur on the condition of anonymity. According to the field survey results, there were many problems involving street lightings, widow positioning, and piloti in the natural surveillance aspect. As for access control, there were problems related to main entrances and windows without security devices, deserted houses, and side walls with exposed gas pipes. In the maintenance aspect, it was necessary to repair the deteriorated houses. 


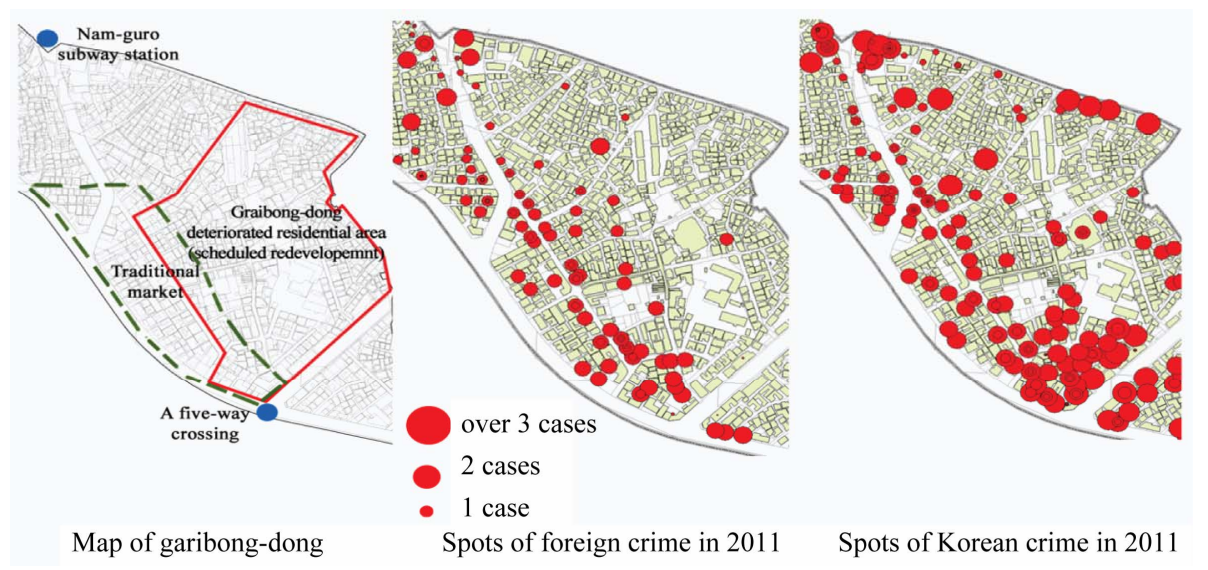

Figure 2. Crime spots in Garibong-dong in 2001.

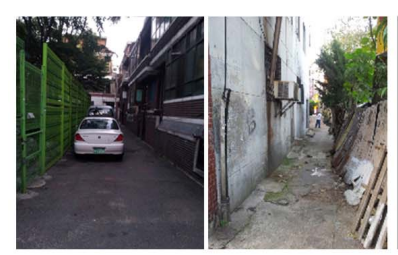

Alley and street

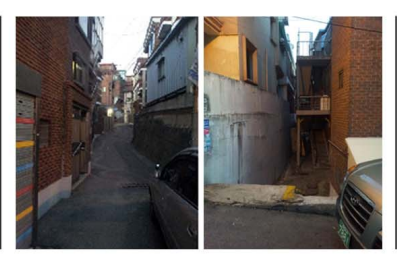

Residential area

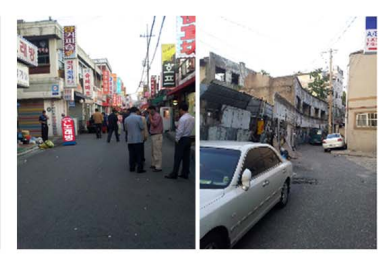

Commercial area

Figure 3. The present conditions of Garibong-dong.

\section{c) Commercial area}

There were many problems concerning the location of lighting around the commercial facilities, windows partially obstructed by advertising media, and some commercial facilities' inadequate positioning, which created entrapment spots in the natural surveillance aspect.

In the access control aspect, there were problems with the insufficiency of security devices in each building and CCTV around the traditional market. In the maintenance aspect, it was necessary to repair the deteriorated buildings, messy streets, and signboards of the commercial buildings to create a safe milieu.

\subsection{Case of Wongok-Dong}

(1) Analysis of crime spots

The number of crimes that occurred in 2011 was 276 . The cases of Korean crime numbered 126, and the case of foreign crime numbered 150 (robbery-8, sexual offences-6, violence-136). Foreign crimes occurred all over the target area, such as around inns, the traditional market, the neighborhood park, and the residential area. However, Korean crimes tended to be concentrated in a specific area as shown in Figure 4.

(2) Field survey results

There were many foreigners of various nationalities residing in Wongok-dong. The research area encompassed the main street and An-san subway station in the south, Wongok-park (neighborhood park) in the north, and the traditional market throughout the area. This area has attracted foreigners due to political concerns and the availability of multi-family rental properties for foreigners in the low-income bracket. The present conditions of alleyway, residential area, and commercial area in Wongok-dong are as shown in Figure 5.

a) Alley and street.

Because the alley was wide and visible, there were many opportunities for natural surveillance. As for access control, there was CCTV in the intersection, but the number of CCTVs was insufficient for crime prevention. In the maintenance aspect, the conditions on the street and of all sorts of street facilities were favorable. However, territoriality reinforcement was insufficient for creating a small community space for residents to enjoy and for projecting public designs on the walls of buildings.

b) Residential area: detached houses, multi-family houses, and row houses

A vulnerable environment was fostered under building spaces and in the narrow spaces between buildings in the form of blind spots in the natural surveillance aspect. In the access control aspect, main entrances and windows were vulnerable because of a lack of security devices, and side walls were vulnerable because of exposed gas pipes. In the maintenance aspect, the residential area was well managed.

c) Commercial area

There were some problems with the lightings around commercial facilities and with windows partially obstructed by advertising media. As for access control, this 


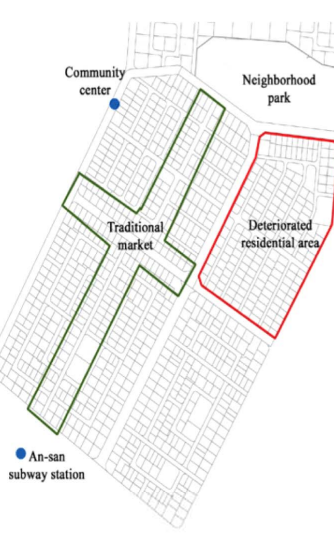

Map of wongok-dong

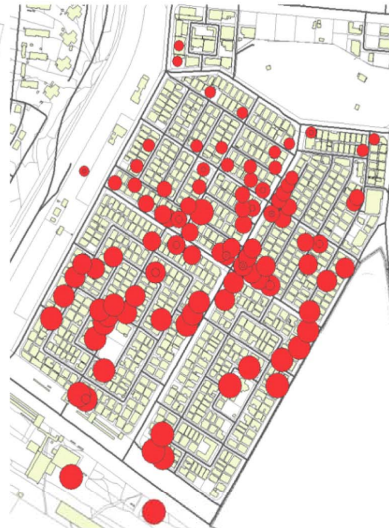

over 3 cases 2 cases $\quad 1$ case

Spots of foreign crime in 2011

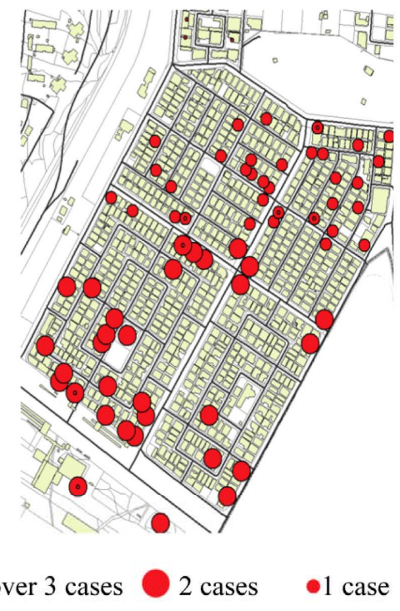

Spots of Korean crime in 2011

Figure 4. Crime spots in Wongok-dong in 2001.

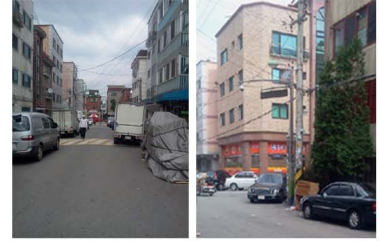

Alley and street

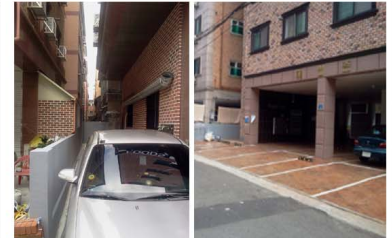

Residential area

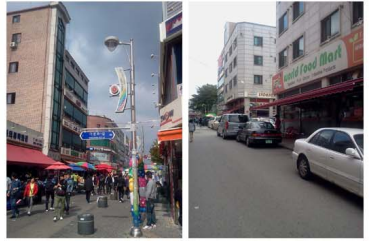

Commercial area

Figure 5. The present conditions of Wongok-dong.

area was favorably assessed in terms of a security kiosk and CCTV in the main intersection of the residential area and traditional market. In the maintenance aspect, the commercial area and traditional market were well managed.

\subsection{Comprehensive Review of the Field Survey and Hot-Spot Analysis}

A summary of the field survey and hot-spot analysis is as follows. The main type of foreign crime that occurred in the research area was violence, and the hot-spot was concentrated in the area surrounding the subway stations, traditional markets, merrymaking places, and residential areas adjacent to commercial facilities. There were many problems in Garibong-dong (refer to Table 1), but Wongok-dong was favorably assessed from the view of CPTED (refer to Table 2).

In the case of Garibong-dong, there were insufficient security facilities such as lighting and CCTV, and the poor condition of the residential area was attributed to the proliferation of narrow and curved paths, which connected repeatedly, and to the close proximity of deteriorating houses of houses of various sizes.

In the case of Wongok-dong, there were many foreigners of various nationalities and residential and commercial facilities for them. Also, there were visible and well managed streets arranged in a lattice configuration and sufficient security facilities due to the fact that it was a planned city, as opposed to Garibong-dong. However, there were problems related to piloti space under the buildings, narrow spaces with blind spots between the buildings, main entrances and windows without security devices, and side walls with exposed gas pipes. According to these results, it was inferred that the occurrence of crime was related to land use, street characteristics, and security facilities, similar to the findings discussed in the literature review. Foreigners lived in the residential area adjacent to the traditional market, where commercial facilities stood close together. Therefore, it seemed that the environmental elements that cause crime existed in those areas.

In contrast, crimes committed by Koreans, which were mainly violence and crimes such as burglary, theft, robbery, and sexual offences, occurred steadily. It was inferred that the environment had influenced various crimes, because the spaces that were assessed to be vulnerable to crime by the field survey were similar to the hot-spots for crime committed by Koreans.

\subsection{Crime Prevention Measures for Foreign Residential Areas}

The following measures are deemed necessary for pre- 
Table 1. Crime risk assessment of Garibong-dong by field survey.

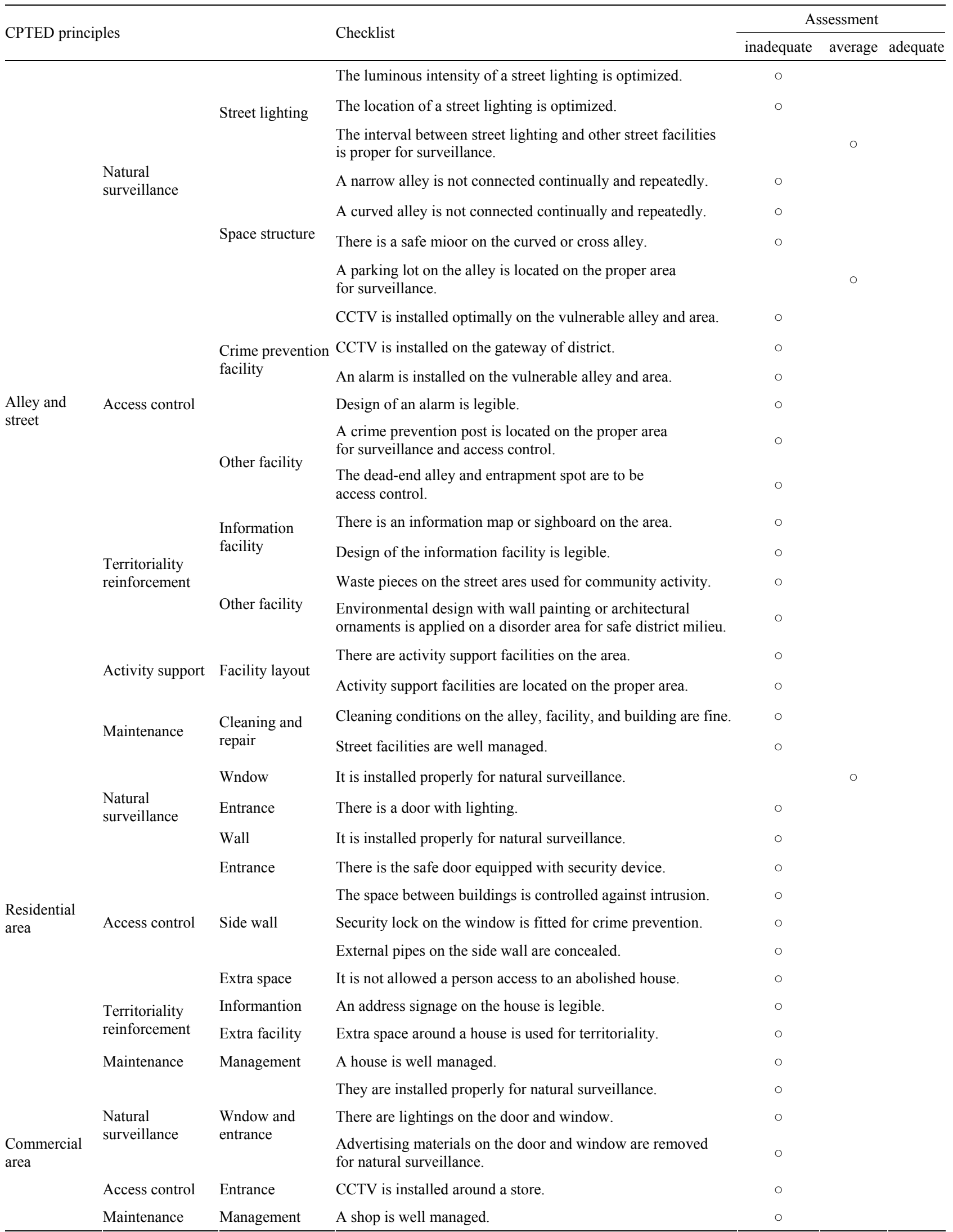


Table 2. Crime risk assessment of Wongok-dong by field survey.

\begin{tabular}{|c|c|c|c|c|c|c|}
\hline \multirow{2}{*}{\multicolumn{2}{|c|}{ CPTED principles }} & & \multirow{2}{*}{ Checklist } & \multicolumn{3}{|c|}{ Assessment } \\
\hline & & & & Inadequate & Average & Adequate \\
\hline \multirow{21}{*}{$\begin{array}{l}\text { Alley and } \\
\text { street }\end{array}$} & \multirow{7}{*}{$\begin{array}{l}\text { Natural } \\
\text { surveillance }\end{array}$} & \multirow{3}{*}{ Street lighting } & The luminous intensity of a street lighting is optimized. & & O & \\
\hline & & & The location of a street lighting is optimized. & & O & \\
\hline & & & $\begin{array}{l}\text { The interval between street lighting and other street facilities } \\
\text { is proper for surveillance. }\end{array}$ & & 0 & \\
\hline & & \multirow{4}{*}{ Space structure } & A narrow alley is not connected continually and repeatedly. & & & O \\
\hline & & & A curved alley is not connected continually and repeatedly. & & & 0 \\
\hline & & & There is a safe mioor on the curved or cross alley. & O & & \\
\hline & & & $\begin{array}{l}\text { A parking lot on the alley is located on the proper area } \\
\text { for surveillance. }\end{array}$ & & & 0 \\
\hline & \multirow{6}{*}{ Access control } & \multirow{4}{*}{$\begin{array}{l}\text { Crime preventio } \\
\text { facility }\end{array}$} & CCTV is installed optimally on the vulnerable alley and area. & & 0 & \\
\hline & & & ${ }_{n}$ CCTV is installed on the gateway of district. & & O & \\
\hline & & & An alarm is installed on the vulnerable alley and area. & O & & \\
\hline & & & Design of an alarm is legible. & O & & \\
\hline & & \multirow{2}{*}{ Other facility } & $\begin{array}{l}\text { A crime prevention post is located on the proper area } \\
\text { for surveillance and access control. }\end{array}$ & & 0 & \\
\hline & & & The dead-end alley and entrapment spot are to be access control. & & O & \\
\hline & \multirow{4}{*}{$\begin{array}{l}\text { Territoriality } \\
\text { reinforcement }\end{array}$} & \multirow{2}{*}{$\begin{array}{l}\text { Information } \\
\text { facility }\end{array}$} & There is an information amp or sighboard on the area. & & 0 & \\
\hline & & & Design of information facility is legible. & O & & \\
\hline & & \multirow[b]{2}{*}{ Other facility } & Waste pieces on the street are used for community activity. & O & & \\
\hline & & & $\begin{array}{l}\text { Environmental design with wall painting or architectural } \\
\text { ornaments is applied on a disorder area for safe district milieu. }\end{array}$ & O & & \\
\hline & \multirow{2}{*}{ Activity support } & \multirow{2}{*}{ Facility layout } & There are activity support facility and space on the area. & & 0 & \\
\hline & & & Activity support facilities are located on the proper area. & & 0 & \\
\hline & \multirow{2}{*}{ Maintenance } & \multirow{2}{*}{$\begin{array}{l}\text { Cleaning and } \\
\text { repair }\end{array}$} & Cleaning conditions on the alley, facility, and building are fine. & & & 0 \\
\hline & & & Street facilities are well managed. & & & $\circ$ \\
\hline \multirow{11}{*}{$\begin{array}{l}\text { Residential } \\
\text { area }\end{array}$} & \multirow{3}{*}{$\begin{array}{l}\text { Natural } \\
\text { surveillance }\end{array}$} & Wndow & It is installed properly for natural surveillance. & & O & \\
\hline & & Entrance & There is a door with lighting. & O & & \\
\hline & & Wall & It is installed properly for natural surveillance. & & O & \\
\hline & \multirow{5}{*}{ Access control } & Entrance & There is the safe door equipped with security device. & & O & \\
\hline & & \multirow{3}{*}{ Side wall } & The space between buildings is controlled against intrusion. & O & & \\
\hline & & & Security lock on the window is fitted for crime prevention. & & O & \\
\hline & & & External pipes on the side wall are concealed. & 0 & & \\
\hline & & Extra space & It is not allowed a person access to an abolished house. & & & 0 \\
\hline & \multirow{2}{*}{$\begin{array}{l}\text { Territoriality } \\
\text { reinforcement }\end{array}$} & Informantion & An address signage on the house is legible. & & 0 & \\
\hline & & Extra facility & Extra space around a house is used for territoriality. & O & & \\
\hline & Maintenance & Management & A house is well managed. & & & 0 \\
\hline \multirow{5}{*}{$\begin{array}{l}\text { Commercial } \\
\text { area }\end{array}$} & \multirow{3}{*}{$\begin{array}{l}\text { Natural } \\
\text { surveillance }\end{array}$} & \multirow{3}{*}{$\begin{array}{l}\text { Wndow and } \\
\text { entrance }\end{array}$} & They are installed properly for natural surveillance. & & O & \\
\hline & & & There are lightings on the door and window. & O & & \\
\hline & & & $\begin{array}{l}\text { Advertising materials on the door and window are removed } \\
\text { for natural surveillance. }\end{array}$ & O & & \\
\hline & Access control & Entrance & CCTV is installed around a store. & & 0 & \\
\hline & Maintenance & Management & A shop is well managed. & & O & \\
\hline
\end{tabular}


vention of crime in foreign residential areas. Comprehensive environmental improvement is necessary for crime prevention in Garibong-dong, where there are insufficient urban infrastructures and deteriorating residential facilities. CCTV, public lighting, and security alarms especially needs to be increased and the traditional markets need to be modernized.

Because it will take a certain period of time to improve the environment of the deteriorating district, it is necessary to make a community space for activity support and to reinforce patrol by the police or self-defense watchmen in the short term, and to guide the architectural design of the area according to CPTED principles and to convert an inn and a pub in the residential area into wholesome land use in the long term.

To put it concretely, the target hardening measures must be applied to the narrow spaces with blind spots between the buildings, the main entrances, and windows without security devices, and side walls with exposed gas pipes to prevent crimes such as burglary, theft, and robbery, in consideration of the deteriorating buildings and space structure.

In the case of Wongok-dong, it is necessary to reinforce crime prevention measures in the commercial area verified as a hot-spot, to close-in the residential area and to increase the number of lighting and alarm and to improve degree of visibility on the commercial facilities' window in view of CPTED.

And likewise the Garibong-dong case, it is necessary to apply concept of the target hardening and natural surveillance measures on a blind spot between the buildings, piloti space, and side wall space against burglary and robbery.

\section{Conclusions}

Until now, the crime prevention strategies proposed by government and municipality are summarized as CCTV installation and reinforcement of police patrol. However these strategies are not enough to deal with various crimes committed in everywhere. Under these circumstances, CPTED could be an alternative strategy for crime prevention to environment condition.

As CPTED application is important for establishing safety infra $\mathrm{n}$ society through environmental design and management $[6,7,19]$, it is suggested to be considered a mandatory standard on architectural and urban planning for crime prevention.

In this study, much of crime related violence had been committed in the ethnic area. Moreover, a number of certain crimes such as burglary and robbery increased steadily. Because crimes are related to the urban planning elements comprised of land use such as traditional market, inn, pub, and complicated space structure and the architectural design for natural surveillance and security facilities such as CCTV, lighting, alarm, and target hardening device, a new strategy for crime prevention design should include street environmental management, improvement of commercial facilities, and reinforcement security device of each buildings has to be spread through support of policy. Also the design for community activation is recommended to be applied on public space and installed CCTV and alarm with a siren on the gateway of district, an intersection, and entrapment spots.

Finally it is necessary to reinforce the function of existing self-defense watchmen and a night patrol by the police on the commercial area for foreigners. In conclusion it was thought that CPTED would be a valuable measure to prevention crime and support community activities in ethnic area as expecting an improvement of physical environment and resident participatory for safer community.

\section{REFERENCES}

[1] C.-H. Kim and H.-K. Ahn, "Spatial Distribution and Causes of Foreign Residential Areas in Seoul Metropolitan Area by Immigration Circuits: focused on Professional and Working groups," Journal of Korea Planners Association, Vol. 46, No. 5, 2011, pp. 233-248.

[2] S.-H. Park and S.-Y. Jung, "Spatial Distribution of Foreign Population and Policy Implication in South Korea," The Korea Spatial Planning Review, Vol. 64, No. 4, 2010, pp. 59-76.

[3] S.-H. Park, Y.-A Lee, E.-R. Kim and S.-Y. Jung, "Reinventing Urban Policy in Response to Ethnic Diversity: A Report on Emerging Ethnic Places in South Korea," Korea Research Institute For Human Settlements, Anyang-Si, 2009.

[4] J.-E. Jung, G.-S. Ha and J.-M. Jun, "Analysis on the Determinants of Residential Location Choice for Foreign Residents in the Seoul Metropolitan Region," Journal of Korea Planners Association, Vol. 46, No. 6, 2011, pp. 117-130.

[5] J.-O. Kim, "A Study on the Felony of Foreign Laborer," Korean Journal of Public Safety and Criminal Justice, Vol. 37, No. 4, 2009, pp. 97-127.

[6] T. D. Crowe, "Crime Prevention through Environmental Design: Applications of Architectural Design and Space Management Concepts," Butterworth-Heinemann, Oxford, 2000.

[7] C. R. Jeffery, "Crime Prevention through Environmental Design," Sage Publications, 1972.

[8] E. R. Groff, "Exploring the Geography of Routine Activity Theory: A Spatio-Temporal Test Using Street Robbery," Ph.D. Thesis, University of Maryland, College Park, 2006.

[9] R. V. Clarke and M. Felson, "Routine Activity and Rational Choice," New Brunswick, New Jersey, 2004.

[10] R. V. Clarke, "Situational Crime Prevention: Successful 
Case Studies," 2nd Edition, Criminal Justice Press, New York, 1997.

[11] B. B. Brown, "Territoriality, Street Form, and Residential Burglary: Social and Environmental Analyses," Ph.D. Thesis, University of Utah, Salt Lake City, 1983.

[12] B. Yuen, "Safety and Dwelling in Singapore," Cities, Vol. 21, No. 1, 2004, pp. 19-28. doi:10.1016/j.cities.2003.10.005

[13] P. L. Brantingham and P. J. Brantingham, "Nodes, Paths and Edges: Considerations on the Complexity of Crime and the Physical Environment," Journal of Environmental Psychology, Vol. 13, No. 1, 1993, pp. 3-28. doi:10.1016/S0272-444(05)80212-9

[14] E. R. Groff and N. G. La Vigne, "Mapping an Opportunity Surface of Residential Burglary," Journal of Research in Crime and Delinquency, Vol. 38, No. 3, 2001, pp. 257-278. doi: $10.1177 / 0022427801038003003$

[15] J. E. Macdonald and R. Gifford, "Territoriality Cues and Defensible Space Theory: The Burglar's Point of View," Journal of Environmental Psychology, Vol. 9, No. 3, 1989, pp. 193-205. doi: 10.016/S0272-4944(89)80034-9

[16] K.-H. Lee, "Community and Burglary in the Urban Residential Street Block: An Environmental Analysis," Ph.D. Thesis, University of Wisconsin-Milwaukee, 1992.

[17] L. Brunson, F. E. Kuo and W. C. Sullivan, "Resident Appropriation of Defensible Space in Public Housing," Environment and Behavior, Vol. 33, No. 5, 2001, pp. 626-
652. doi: $10.1177 / 00139160121973160$

[18] M. Taylor and C. Nee, "The Role of Cues in Simulated Residential Burglary," British Journal of Criminal, Vol. 28, No. 3, 1988, pp. 396-401.

[19] O. Newman, "Defensible Space," Macmillan Publishing Co. Inc., London, 1972.

[20] R. B. Taylor and S. D. Gottfredson, "Territoriality, Defensible Space, Informal Social Control Mechanical, and Community Crime Prevention," Johns Hopkins University, Baltimore, 1978.

[21] R. B. Taylor, S. A. Shumaker and S. D. Gottfredson, "Neighborhood-Level Links between Physical Features and Local Sentiments," Journal of Architectural and Planning Research, Vol. 2, 1985, pp. 261-275.

[22] W. M. Rohe and R. J. Burby, "Fear of Crime in Public Housing," Environment and Behavior, Vol. 20, No. 6, 1988, pp. 700-720. doi: 10.1177/0013916588206003

[23] S.-J. Kang and K.-H. Lee, "A Research on Creating Crime-Safe Environment Through Enforcing the Sense of Community in Urban Residential Area," Journal of the Architectural Institute of KOREA, Vol. 23, No. 7, 2007, pp. 97-106.

[24] S.-J. Kang and K.-H. Lee, "A Study on the Relationships of Outdoor Space Activation and the Experienced Crime Victimization Rate in Multi-Family Housings," Journal of the Architectural Institute of KOREA, Vol. 20, No. 2 , 2004, pp. 71-78. 